\title{
Adaptive strategies in populations of Chirocephalus diaphanus (Crustacea, Anostraca) from temporary waters in the Reatine Apennines (Central Italy)
}

\author{
Graziella MURA*, Giovanni FANCELLO and Secondina DI GIUSEPPE \\ Dipartimento di Biologia Animale e dell'Uomo, Università "La Sapienza", Viale dell'Università 32, 00185 Roma, Italy \\ *e-mail corresponding author:graziella.mura@uniroma1.it
}

\begin{abstract}
To investigate the relationship between the adaptive strategies of Chirocephalus diaphanus (Crustacea, Anostraca) and the environmental characteristics of its habitat, we studied two populations living in high-altitude biotopes with very different characteristics, i.e. a semipermanent pool (Tilia Lake) and a temporary one (Illica Plain Pool), and we examined the essential features of their biological cycles (growth rate, reproductive biology, sex ratio and life cycle). The results show that the two populations adjust to the biotopes in which they live, fully exploiting the brief period available for development, in agreement with hypotheses formulated in studies of other colonizers of temporary environments. The strategy adopted by the Chirocephalus diaphanus population of Tilia Lake, a predictable and relatively constant environment, is similar to the $\mathrm{k}$ type, characterized by slow growth, late reproduction and a long life cycle. In contrast, the Illica Plain population presents rapid growth, precocious reproduction and a short life cycle, since it is highly dependent on the precariousness and unpredictability of the pool in which it lives.
\end{abstract}

Key words: Anostraca, Chirocephalus diaphanus, life history, temporary waters, environmetal diversity, adaptive strategies

\section{INTRODUCTION}

The life cycle of organisms, in its phenotypic expressions, represents a series of selective compromises imposed by different environmental variables. Natural selection will modify the characteristics of the life cycle to produce an adaptive strategy that optimizes individual fitness and synthesizes the compromise between the various selective pressures (Wilbur et al. 1974). The strategies adopted by populations of a species are related to the population density-trophic resources relationship (Pianka 1970; Gadgil \& Solbrig 1972), to stress from predatory pressure and competition (Hamer \& Appleton 1991), and to the duration of the colonized biotope (Marcus \& Weeks 1997).

To evaluate the importance of the duration and stability of the biotope in anostracan crustaceans typically confined to temporary water bodies, we chose two populations of Chirocephalus diaphanus living in biotopes with different environmental characteristics. The two pools are in the central Apennines north of Rome in an area with winter snowfalls and dry summers, and they both present a spring-summer cycle. However, although at roughly the same altitude and thus exposed to the same photoperiod and similar thermal regime, they differ in the predictability and stability of their water phase

\subsection{The species}

Chirocephalus diaphanus Prévost 1803 is the most diffuse and tolerant species of the genus in Italy. For this reason, it is able to colonize temporary environments both at sea level and at high altitude. The tem- perature range in which it normally lives is very wide $\left(5-26{ }^{\circ} \mathrm{C}\right)$ (Nourisson 1964), and there are occasional records of it in pools covered by a thick layer of ice (Hall 1961) or at temperatures above $30{ }^{\circ} \mathrm{C}$ (Mura 1991). Depending on the altitude of the colonized biotope, the biological cycle of different populations can be autumn-winter, with a summer stasis due to disappearance of the water, or spring-summer with a winter stasis due to freezing. Except for sporadic cases, Chirocephalus diaphanus usually has a univoltine cycle (Cottarelli 1966).

\subsection{The study sites}

Tilia Lake (1591 m a.s.1.) is a semipermanent highpasture pool on Mount Tilia (1775 m a.s.l.) near Leonessa (Rieti) (Cottarelli 1966). The pool, with a maximum depth of $97 \mathrm{~cm}$, has a roughly rectangular shape $(54 \times 48 \mathrm{~m})$. Its total surface area is $2592 \mathrm{~m}^{2}$ and its estimated volume is $474.3 \mathrm{~m}^{3}$. The water cycle begins with the melting of the snow, normally between March and April, followed by a variable period in which the water level oscillates depending on the temperature and precipitation. However, the pool rarely dries up completely.

Illica Plain Pool (1485 m a.s.1.) on Mount Inversaturo in the Laga Mountains is a small, oblong temporary water body $(25 \times 16 \mathrm{~m})$. It has a surface area of 264 $\mathrm{m}^{2}$, a maximum depth of $50 \mathrm{~cm}$ and a volume of 87.8 $\mathrm{m}^{3}$. This pool also has a spring-summer cycle. However, because of its morphological and geological characteristics, it is characterized by erratic, short-term filling and it often dries up before the animals can reach reproductive age. 
a

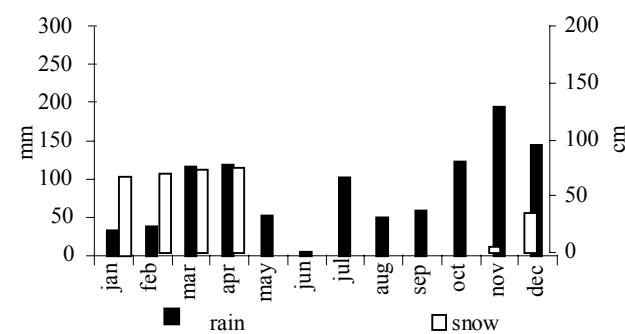

C

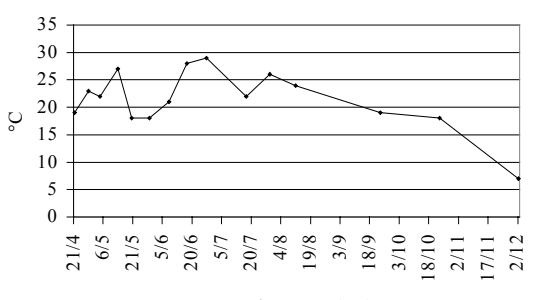

- air temp. $\left({ }^{\circ} \mathrm{C}\right)$

e

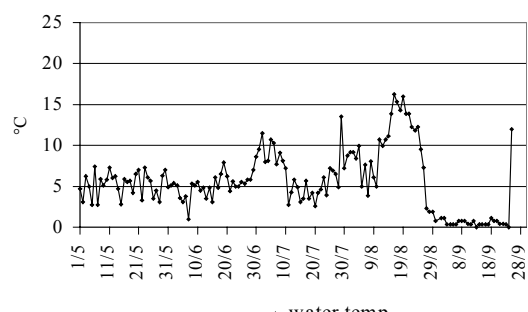

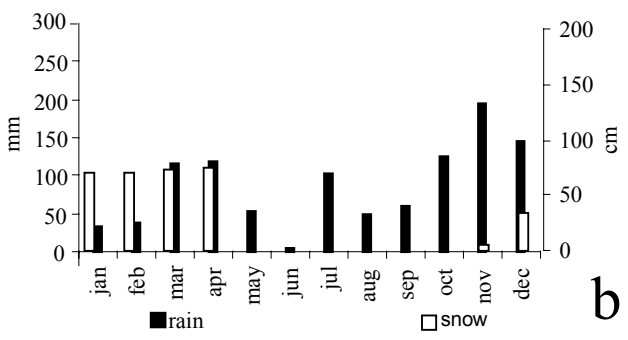

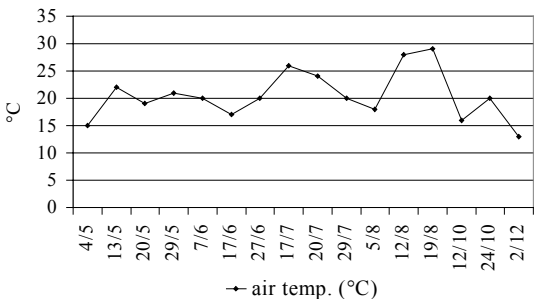

d

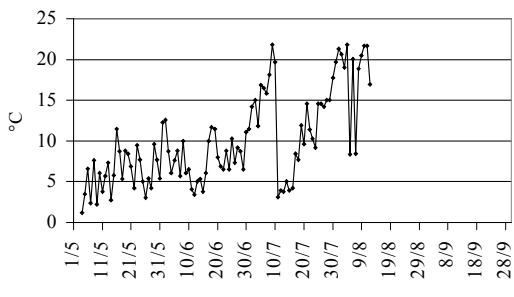

- water temp.

Fig. 1. Seasonal variations of air and water temperature and precipitations during 2000 at Tilia Lake (a, c, e) and Illica Pool pool (b, d, f).

\section{METHODS}

Between April and August 2000, the two biotopes were monitored on a weekly basis to evaluate the fluctuations of environmental conditions and to record information about the basic characteristics of the life cycle of the animals.

The abiotic environment was characterized by observation of the climatic pattern and measurement of the main chemical and physical variables (water temperature, $\mathrm{pH}$, electrical conductivity, total dissolved solids, surface area and volume of the pools). Particular attention was given to the oscillations of water temperature, in view of its strong influence on the life of aquatic organisms (Lake 1969). For this purpose, we installed a continuous measurement probe in the two pools, which allowed a detailed analysis of the temperature excursions throughout the water cycle.

The biological cycles of the two populations were examined by periodic sampling, which provided information about the growth rate of the animals, their rate of differentiation and sexual maturation, and the sex ratio. The material sampled on each visit was divided by developmental stage and measured with a micrometric eyepiece mounted on a stereomicroscope. When the duration of the cycle permitted it, we also collected data on the fertility of the two populations: we isolated the females of each sample and counted the number of cysts laid in order to estimate the mean brood size in relation to the increasing size of the animals. All the data for the two biotopes were analyzed statistically (STATISTICA '98 for Windows, STATSOFT Inc ${ }^{\circledR}$ ) to reveal any significant differences.

\section{RESULTS}

\subsection{Characteristics of the biotopes}

Tilia Lake. The water-phase began on April $21^{\text {st }}$ and the water level remained constant until mid-May. Then there was a phase of constant decline due to evaporation and lack of precipitation. In July, unusual rainfall caused the water level to rise again, but there was a subsequent decline until the beginning of autumn, when new rainfall led to full capacity of the pool.

Illica Plain pool. The water-phase began on May $3^{\text {rd }}$ and there were alternate phases of decline and filling of the pool until it dried completely on August $19^{\text {th }}$. The pool then filled again but did not reach full capacity. A phase of decline began on October $1^{\text {st }}$ and lasted for 20 days, after which rainfall again filled the pool to its maximum volume.

The statistical comparison of the climatic data showed that the two biotopes had a very similar weather pattern (rainfall, snowfall, air temperature) (Figs 1 a-f) in the study year (2000); in fact, there were no significant differences between the two areas (ANCOVA, P $>0.05$ ). 

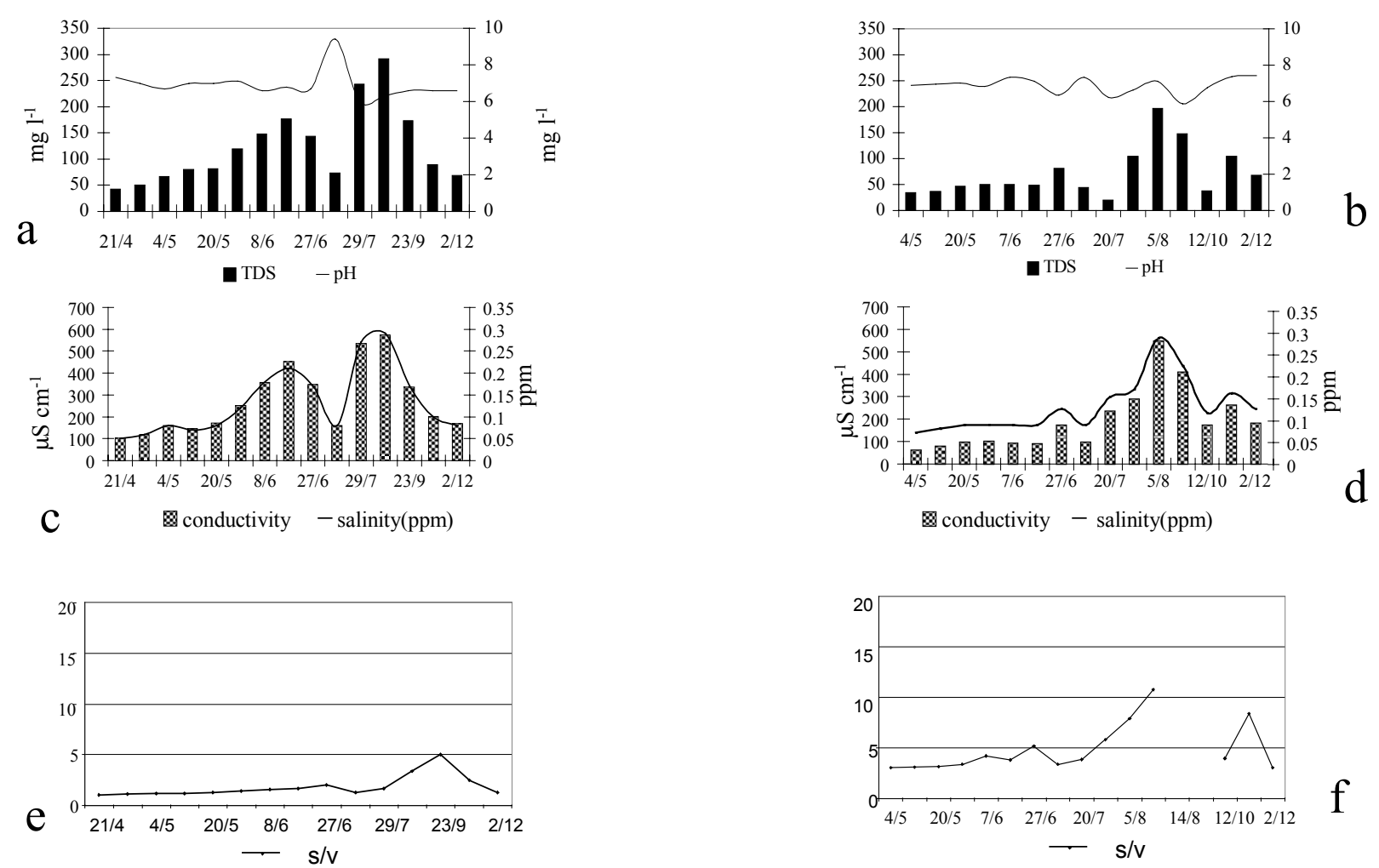

Fig. 2. Fluctuations of the main environmental variables during 2000 in Tilia Lake (a, c, e) and Illica Plain pool (b, d, f). TDS = total dissolved solids; $\mathrm{s} / \mathrm{v}=$ surface/volume ratio.
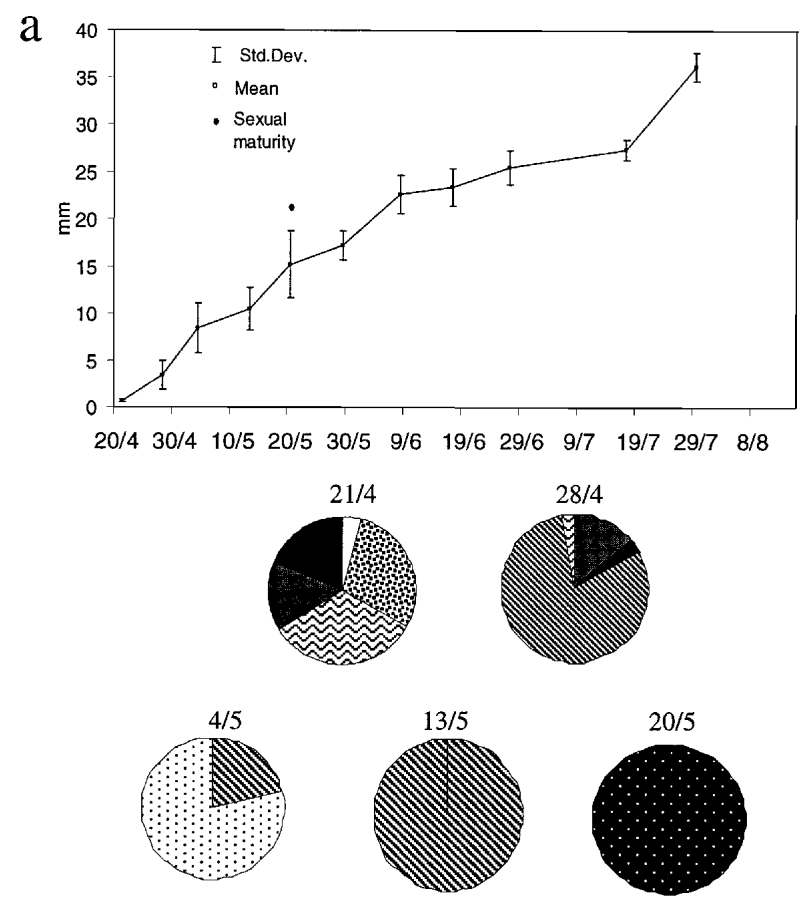

$\square$ nauplii

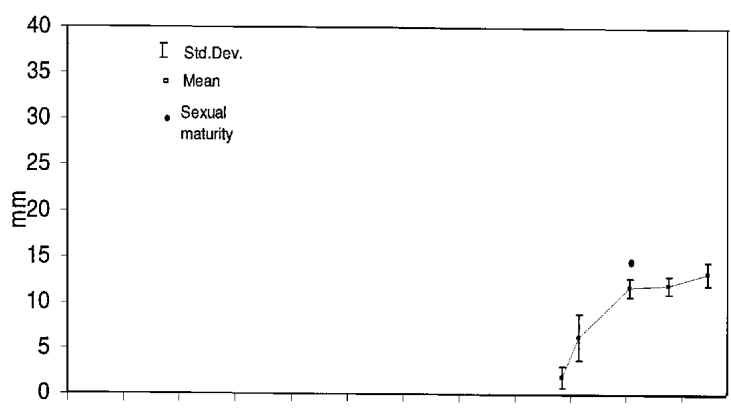

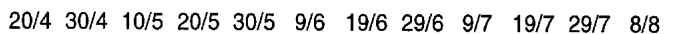
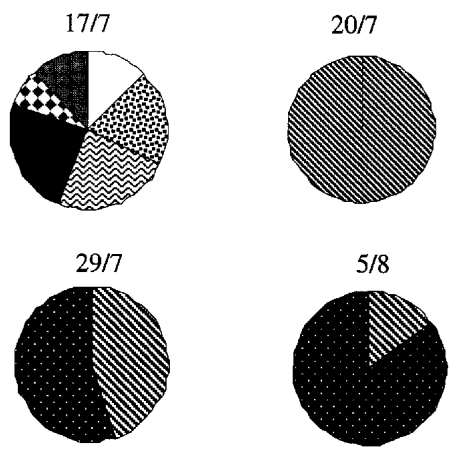

metanauplii (IV) metanauplii (V)

$$
\mathbf{0} \text { metanauplii (VI) juvenes } \quad \text { adults 非 }
$$

Fig. 3. Life cycle of Chirocephalus diaphanus in Tilia Lake (a) and in Illica Plain pool (b). 
A comparison ( $\mathrm{t}$-test) of the physico-chemical variables of the two pools during the year (Figs 2 a- $f$ ) yielded a similar result. However, analysis of the daily excursion in water temperature (Figs $1 \mathrm{e}, \mathrm{f}$ ), a direct expression of the model of fluctuation of this variable, revealed highly significant differences between the two pools ( $\mathrm{P}<0.001)$, likely due to their different size and depth.

There were also significant differences $(\mathrm{P}<0.05)$ in the fluctuations of the surface area/volume ratio of the two pools (Figs 2 e, f), which provides an indirect measure of their evaporation rate.

\subsection{Life history}

In Tilia Lake, the first nauplii appeared on April $21^{\text {st }}$ (Fig. 3a), while the last individuals disappeared from the pool 100 days later on July $29^{\text {th }}$, at a mean size of $36.1 \pm$ $1.5 \mathrm{~mm}$ (range $34-37.5 \mathrm{~mm}$ ).

The mean growth rate was $0.5 \mathrm{~mm}$ per day until sexual maturity, which was followed by a decrease of $0.3 \mathrm{~mm}$ per day. Differentiation of the juveniles occurred in 13 days at a mean size of $9.3 \pm 2.3 \mathrm{~mm}$ (range 6-13 mm), while sexual maturity was reached in 29 days, at a minimum size of $12 \mathrm{~mm}$ for the females $($ mean $=15.2 \pm 3.6 \mathrm{~mm}$, range $12-21 \mathrm{~mm})$.

The Illica Plain pool (Fig. 3b) population lived for only 27 days: the nauplii appeared on July $17^{\text {th }}$ and the last adult specimens were caught on August $12^{\text {th }}$, at a mean size of $13.3 \pm 1.3 \mathrm{~mm}$ (range $12-15.5 \mathrm{~mm}$ ). The mean growth rate was $0.9 \mathrm{~mm}$ until sexual maturity, which was followed by a decrease of $0.1 \mathrm{~mm}$ per day. Sexual differentiation occurred in only 8 days, while sexual maturity was reached in 12 days, at a minimum size of $11 \mathrm{~mm}$ for the females (mean $=12.8 \pm 0.6 \mathrm{~mm}$, range 11-14 $\mathrm{mm}$ ).

As regards the number of eggs per clutch (Tab. 1), the limited overlap of the individual size classes of the two populations and the small sample size of the Illica population did not permit a valid comparison, although the data for the 12 and $15 \mathrm{~cm}$ size classes, the only comparable ones, suggest greater fertility in the Illica population.

From the first appearance of adults, we observed a clear numerical superiority of males in both populations. In the Tilia population (Fig. $4 \mathrm{a}$ ), this progressively decreased and the sex ratio was reversed in the last sampling, perhaps indicating greater physical resistance of the females. In the Illica population, the prevalence of males continued until the population disappeared (Fig. 4 b).

\section{DISCUSSION AND CONCLUSIONS}

Our observations show that the two biotopes, differing in size and in the predictability and stability of filling, impose very different environmental conditions on their respective colonizers, leading to the adoption of distinct adaptive strategies.
In an environment with strong instability, numerous stress factors, with irregular and unpredictable fluctuations, act on the population independently of its size and maintain it well below the carrying capacity (Wilson \& Bossert 1974). In this situation, natural selection favors individuals that tend to maximize their reproduction by adopting an $r$ type strategy, i.e. rapid growth, precocious sexual maturity and short life cycle, so as to successfully overcome environmental adversities.

Tab. 1. Fertility data for Tilia Lake and Illica Plain pool populations during the study year.

\begin{tabular}{|c|c|c|}
\hline $\begin{array}{l}\text { Female length } \\
\qquad(\mathrm{mm})\end{array}$ & $\begin{array}{l}\mathrm{n}^{\circ} \text { ind. } \\
\text { for size class }\end{array}$ & $\begin{array}{c}\text { Cysts } n^{\circ} \\
\text { mean/female }\end{array}$ \\
\hline \multicolumn{3}{|l|}{ Tilia Lake } \\
\hline 12 & 2 & 15 \\
\hline 15 & 4 & 48 \\
\hline 16 & 1 & 46 \\
\hline 17 & 3 & 27 \\
\hline 18 & 7 & 56 \\
\hline 19 & 10 & 80 \\
\hline 20 & 10 & 62 \\
\hline 21 & 6 & 93 \\
\hline 22 & 4 & 115 \\
\hline 23 & 1 & 248 \\
\hline 24 & 2 & 246 \\
\hline 25 & 2 & 488 \\
\hline 26 & 1 & 1261 \\
\hline 27 & 1 & 819 \\
\hline 28 & 1 & 370 \\
\hline 29 & 3 & 553 \\
\hline 30 & 6 & 857 \\
\hline 31 & 6 & 817 \\
\hline 32 & 11 & 789 \\
\hline 33 & 10 & 762 \\
\hline 34 & 6 & 928 \\
\hline 35 & 11 & 893 \\
\hline 36 & 1 & 989 \\
\hline 43 & 1 & 976 \\
\hline \multicolumn{3}{|l|}{ Illica Plain pool } \\
\hline 11 & 12 & 12 \\
\hline 11.5 & 3 & 17 \\
\hline 12 & 1 & 28 \\
\hline 12.5 & 2 & 39 \\
\hline 13 & 6 & 33 \\
\hline 13.5 & 1 & 50 \\
\hline 14 & 3 & 55 \\
\hline 14.5 & 2 & 62 \\
\hline 15 & 5 & 61 \\
\hline 15.5 & 1 & 63 \\
\hline
\end{tabular}

In contrast, in biotopes with limited stress, there may be a situation of density-dependent mortality, in which the population tends to be controlled biologically. In these circumstances, the most appropriate strategy seems to be the k type, with slow growth, late reproduction and a long life cycle. In these conditions, natural selection penalizes a strong investment in reproduction if it reduces the possibility of individual survival (Wilson \& Bossert 1974).

In the present case, the Illica population lives in an unstable and unpredictable pool, whose small size and strong astatism limits the duration of the biological 
a
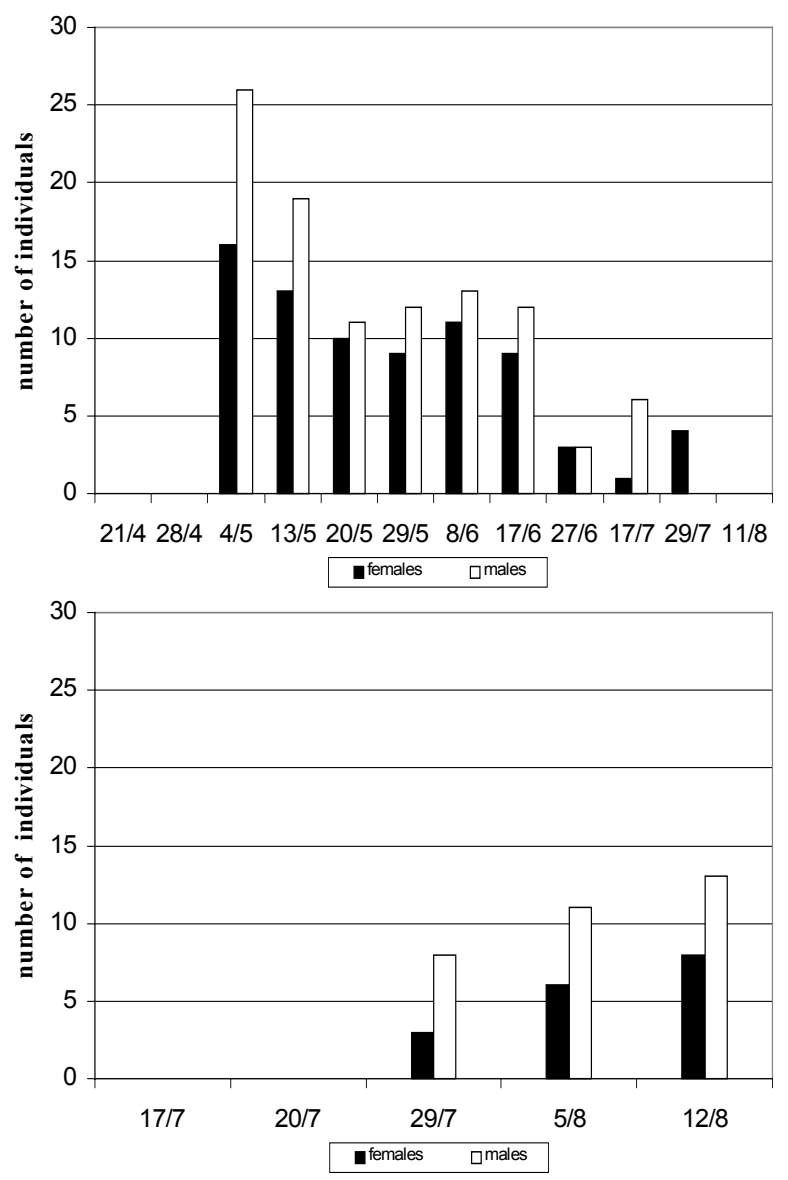

Fig. 4. Pattern of sex ratio of Tilia Lake (a) and Illica Plain pool (b) populations during the study year.

cycle of the animals; thus we would expect that the population would tend to use all the available resources to reach reproductive age and achieve high fertility as quickly as possible. Instead, in Tilia Lake, with much greater size and stability, the colonizing population has a long period in which conditions are favorable for development; hence it should show slower growth and greater longevity.

Our results appear to confirm this hypothesis, at least regarding the growth rate. In fact, the test of parallelism showed that the Illica population had significantly faster growth than the Tilia population $(\mathrm{p}<0.01)$.

Moreover, for both populations, the growth was not uniform but varied depending on the life cycle phase: it was high from birth until sexual maturity and then decreased, in agreement with the findings of various authors (Lake 1969; Daborn 1976; Maynard 1977; Mura 1991, 1993, 1997).

Regarding fertility, the few data seem to agree with expectations: there appeared to be higher fertility in the Illica population, which compensated for the short period available for reproduction.

At the moment, we cannot explain the observed sex ratios, unbalanced in favor of males in both populations.
Previous studies (Weaver 1943; Dexter \& Kuehnle 1948) have attributed this type of ratio to long-term, stable environments, while the opposite would be common in more uncertain environments. Therefore, from the environmental characteristics of the two biotopes, one would expect different situations in the two pools, on the basis of adaptive hypotheses formulated by various authors (Nourisson 1964; Lake 1969; Mura 1995, 2001).

Recent studies of the Mediterranean populations of Branchipus schaefferi, in which a male-biased sex ratio seems fairly common, have revealed that the phenomenon is due to the presence of one or more supranumerary chromosomes that interfere with sex determination (Beladjal et al. 2002). This increases the factors that must be considered to explain a possible asymmetry of this ratio. However, the lack of information about the biotopes inhabited by the above-mentioned populations prevents any correlation of environmental characteristics with the greater or lesser incidence of the observed phenomenon. Therefore, it will be interesting to carry out similar research on the populations examined in laboratory study to clarify the causes of what we observed in the field. 


\section{REFERENCES}

Beladjal, L., T.T.M. Vandekerckhove, B. Muyessen, J. Heyrman, J. de Caesemaeker \& J. Mertens. 2002. Bchromosomes and male-biased sex ratio with paternal inheritance in the fairy shrimp Branchipus schaefferi (Crustacea, Anostraca). Heredity, 88: 356-360.

Cottarelli, V. 1966. Notizie sulla biologia di un crostaceo anostraco: Chirocephalus stagnalis. Arch. Zool. It., 51: 1031-1052.

Daborn, G.R. 1976. The life cycle of Eubranchipus bundyi Forbes (Crustacea: Anostraca) in a temporary vernal pond of Alberta. Can. J. Zool., 54: 193-201.

Dexter, R.W. \& C.H. Kuehnle. 1948. Fairy shrimp populations of north eastern Ohio in the season of 1945 and 1946. Ohio Journal of Science, 48: 15-26.

Gadgil, M. \& T.O. Solbrig. 1972. The concept of r- and k-selection: evidence from wild flowers and some theoretical considerations. Am. Nat., 106: 14-31.

Hall, R.E. 1961. On some aspects of the natural occurrence of Chirocephalus diaphanus Prévost. Hydrobiologia, 17: 205-217.

Hamer, M.L. \& C.C Happleton. 1991. Life history adaptations of phyllopods in response to predators, vegetation, and habitat duration in north-eastern Natal. Hydrobiologia, 212: $105-116$.

Lake, P.S. 1969. The effect of temperature on growth, longevity and egg production in Chirocephalus diaphanus Prévost (Crustacea: Anostraca). Hydrobiologia, 33: 342-351.

Maynard, S.D. 1977. Life history strategies of fairy shrimps (Crustacea: Anostraca) as a function of environmental predictability. Ph.D. Thesis, University of Utah, Salt Lake City, Utah: 135 pp.

Received: December 2002

Accepted: February 2003
Marcus, V. \& S.C. Weeks. 1997. The effects of pond duration on the life history of an ephemeral pond crustacean, Eulimnadia texana. Hydrobiologia, 359: 213-221.

Mura, G. 1991. Life history and interspecies relationships of Chirocephalus diaphanus Prévost and Tanymastix stagnalis (L.), (Crustacea, Anostraca) inhabiting a group of mountain ponds in Latium, Italy. Hydrobiologia, 212: 45-59.

Mura, G. 1993. Habitat and life history of Chirocephalus marchesonii Ruffo \& Vesentini 1957, an endemic fairy shrimp from Monti Sibillini, central Italy. Riv. Idrobiol., 32: 73-104.

Mura, G. 1995. Ecological studies on the fairy shrimps from the temporary waters of Castelporziano Estate (Rome, Latium). Part I: Factors affecting the biology of Chirocephalus diaphanus Prévost and Chirocephalus kerkyrensis Pesta (Crustacea: Anostraca). Riv. Idrobiol., 34: 70-129.

Mura, G. 1997. The life history of Chirocephalus kerkyrensis Pesta (Crustacea, Anostraca) in temporary waters of Circeo National Park (Latium, Italy). Hydrobiologia, 346: 11-23.

Mura, G. 2001b. Life history strategy of Chirocephalus ruffoi (Crustacea, Anostraca) in Mediterranean temporary mountain pools. Hydrobiologia, 462: 145-156.

Nourisson, M. 1964. Existence d'un intervalle de température favorable an développement des öeufs asséchés de Chirocephalus stagnalis Shaw. C. R. Acad. Sci. Paris, 253: 1994-1996.

Pianka, E.R. 1970. On r- and k- selection. Am. Nat., 104: 592-597.

Weaver, C.R. 1943. Observations on the life cycle of the fairy shrimp Eubranchipus vernalis. Ecology, 24: 500-502.

Wilbur, H.M., D.W. Tinkle \& J.P. Collins. 1974. Environmental certainty, trophic level and resource availability in life history evolution. Am. Nat., 108: 805-817.

Wilson, E.O. \& W.H. Bossert. 1974. Introduzione alla biologia delle popolazioni. Piccin Ed.: 197 pp. 